\title{
A EUGENIA LIBERAL: UM OLHAR A PARTIR DA OBRA O FUTURO DA NATUREZA HUMANA DE JÜRGEN HABERMAS
}

\section{THE LIBERAL EUGENICS: A LOOK FROM THE COMPOSITION THE FUTURE OF HUMAN NATURE BY JÜRGEN HABERMAS}

\author{
${ }^{1}$ Riva Sobrado de Freitas \\ ${ }^{2}$ Daniela Zilio
}

\section{RESUMO}

O presente artigo pretende analisar a eugenia liberal a partir do entendimento esposado por Jürgen Habermas na obra O Futuro da Natureza Humana, principalmente no que diz respeito à possibilidade de que o indivíduo exposto a procedimentos de manipulação genética possa ter ferido o seu direito à autocompreensão e, consequentemente, sua dignidade pessoal. $\mathrm{O}$ objetivo, então, coaduna-se na investigação acerca da ideia trazida pelo autor sobre a eugenia liberal e as suas possíveis consequências em relação aos direitos do indivíduo exposto a tal prática. Para tanto, foi realizada uma pesquisa bibliográfica exploratório-explicativa, qualitativa, utilizando-se o método hipotético-dedutivo. Os resultados conquistados com a pesquisa dizem respeito ao estudo do tema sob uma perspectiva filosófica, verificando-se, ainda, que, na ótica do autor, a utilização deliberada de técnicas de manipulação genética torna-se algo perigoso, pelo possível ferimento de direitos do indivíduo objeto de referida manipulação. A conclusão obtida é a de que, de fato, a despeito das inúmeras contribuições trazidas à humanidade pela engenharia genética, existem questões a serem pensadas e, na questão específica da eugenia liberal, o direito à autocompreensão do indivíduo poderia, de certa forma, estar sendo violado no caso de uma intervenção em seu material genético, primordialmente em relação à seleção de características desejáveis. A contribuição alcançada com o presente estudo se pauta no desbravamento de um tema tão importante, e ao mesmo tempo tão polêmico, e que justamente por tal motivo precisa ser analisado, sob o ponto de vista do entendimento da filosofia, mais especificamente à luz da ótica de Jürgen Habermas.

Palavras-chave: Eugenia liberal, Genética, Diagnóstico genético de pré-implantação, Autocompreensão, Dignidade pessoal

\footnotetext{
${ }^{1}$ Doutora em Direito pela Pontifícia Universidade Católica de São Paulo - PUC/SP, São Paulo - SP (Brasil) Professora da Universidade do Oeste de Santa Catarina - UNOESC, Chapecó - SC (Brasil).

E-mail: rivafreit@gmail.com

${ }^{2}$ Mestranda da Universidade do Oeste de Santa Catarina - UNOESC, Chapecó - SC (Brasil).

E-mail: danielazilio@yahoo.com.br
} 


\begin{abstract}
This article intends to analyze the liberal eugenics from the understanding of Jürgen Habermas in the composition The Future of Human Nature, mainly with respect to the possibilities that the subject exposed to genetic manipulation procedures may have hurt its right to self-understanding and, consequently, its personal dignity. The purpose consists in investigating the idea introduced by the author about the liberal eugenics and its possible consequences in relation to the rights of the subject exposed to that practice. Therefore, it was done an exploratory and explanatory bibliographical research, qualitative, using the hypothetical-deductive method. The results achieved with the research are related to the study of the theme through a philosophical perspective, also verifying, that, in the authors point of view, the deliberate use of genetic manipulation techniques is dangerous, by the possibility of hurting the subjects rights, who is the object of this manipulation. The conclusion is that, surely, despite the several contributions brought to the humanity by the genetic engineering, there are issues to be thought and, in the specific issue of the liberal eugenics, the subjects right of self-understanding could, somehow, have been broken in case of intervention in its genetic material, mainly in relation to the selection of the desired characteristics. The contribution achieved with this study is guided in clearing an important theme, and while so polemic, and precisely for this reason needs to be analyzed, by the philosophys point of view, mainly by Jürgen Habermas knowledge.
\end{abstract}

Keywords: Liberal eugenics, Genetic, Genetic diagnosis of preimplantation, Selfunderstanding, Personal dignity 


\section{INTRODUÇÃO}

O estudo em pauta possui como tema central a análise da eugenia, e, mais profundamente, a eugenia liberal, à luz do entendimento de Jürgen Habermas, na obra "O Futuro da Natureza Humana", buscando questionar se a realização da denominada eugenia liberal, relacionada à manipulação genética, pode ferir a autocompreensão do indivíduo em um presente vindouro, e consequentemente, sua dignidade pessoal.

Percebe-se que a discussão acerca da eugenia remonta à antiguidade e, não obstante, hoje em dia, com as técnicas cada vez mais avançadas da ciência, torna-se cada vez mais atual, pautando-se na eventual possibilidade da "construção de seres humanos", daí a importância de uma análise apurada do tema.

Logo, justifica-se o estudo, pois, além de o tema ser extremamente relevante, conforme exposto, vislumbrar o que um estudioso do calibre de Jürgen Habermas externou sobre o assunto, do ponto de vista filosófico, parece primordial para o esclarecimento da pauta, além do enfoque diferenciado que se busca.

O problema a ser verificado, então, embasa-se no questionamento acerca do entendimento de Jürgen Habermas sobre o tema da eugenia liberal, no sentido de saber-se se a intervenção genética poderá gerar danos à autocompreensão do indivíduo submetido a ela ainda na fase pré-pessoal.

Objetiva-se, então, penetrar na teoria Habermasiana, com o intuito de buscar a sua concepção sobre o assunto, tentando, então, trazer um plausível posicionamento acerca da eugenia liberal e do possível comprometimento de direitos do indivíduo. Especificamente, objetiva-se entender o que é a eugenia, e qual é a diferença existente entre eugenia positiva e eugenia negativa. Após, objetiva-se vislumbrar o que trouxe Jürgen Habermas na obra "O Futuro da Natureza Humana”, especialmente no que toca à eugenia liberal, e, por fim, objetiva-se esclarecer se, na visão do autor, a eugenia liberal pode violar a autocompreensão futura, e a consequente dignidade pessoal do indivíduo submetido a procedimentos de manipulação genética.

Para alcançar tal intento, primeiramente será ponderado o conceito de eugenia, e de eugenia positiva e negativa, eis que o entendimento de tais expressões é pressuposto para o entendimento do estudo como um todo. Após, verificar-se-á o entendimento externado por Jürgen Habermas em "O Futuro da Natureza Humana", principalmente no que concerne ao conceito de eugenia liberal, cerne de sua discussão. Finalmente, questionar-se-á se, e em que 
medida, pode a eugenia liberal interferir, e possivelmente ferir, a autocompreensão do indivíduo objeto da intervenção genética, enquanto ser igual, pertencente à espécie e ao todo social, mitigando, consequentemente, a sua dignidade pessoal.

Em relação ao aspecto metodológico, a pesquisa funda-se em procedimentos técnicos, racionais e sistemáticos, com o intento de embasamento científico, proporcionando alicerces lógicos à investigação. Trata-se, por fim, de pesquisa de coleta bibliográfica exploratório-explicativa, qualitativa, em que é utilizado o método hipotético-dedutivo, e em que se tem a finalidade de, partindo de hipóteses, explorar e descrever o tema em comento, exprimindo-se as possíveis soluções para o embate que se expõe, sem, todavia, esgotar-se a temática.

\section{EUGENIA: NECESSÁRIA CONCEITUAÇÃO}

A procura pelo desenvolvimento de seres humanos mais fortes e saudáveis sempre teve vez, independentemente do local e do momento histórico que se esteja tratando. A tecnologia, por sua vez, possibilita que experiências antes nunca imaginadas sejam colocadas em prática.

Sendo assim, pode-se vislumbrar que o avanço da ciência trouxe, sem a menor sombra de dúvidas, grandes contribuições para a humanidade moderna. Porém, junto das contribuições, surgiram também dúvidas, contradições e questionamentos éticos, morais, jurídicos e filosóficos.

O caso da eugenia não é diferente, a sua realização está impregnada de dificuldades.

Pois bem, antes de se buscar o entendimento Habermasiano acerca do assunto, é imprescindível que se conceitue do que se trata a eugenia.

Segundo Melo (2008), é na medicina e na biologia que se deve procurar pelo eugenismo clássico, os textos eugênicos do período do século XIX até 1945 são muitos e com frequência da autoria de médicos e biólogos preocupados em fazer melhoramentos na espécie humana ou em travar a sua degenerescência. Assim, a palavra eugenics é um neologismo e está associada ao nascimento da biologia moderna, principalmente ao darwinismo. $\mathrm{O}$ autor do neologismo seria Francis Galton, médico e matemático, e as definições dadas por ele ao substantivo focam no objetivo da elevação das qualidades raciais das gerações futuras. 
Francis Galton foi extremamente influenciado por Charles Darwin e a questão levantada por este autor no que se relaciona à seleção natural, onde somente os indivíduos mais fortes (aptos) sobrevivem. Darwin, inclusive, era primo de Galton.

Então, Francis Galton teria proposto que essa seleção fosse complementada por uma seleção artificial, socialmente controlada, de acordo com Melo (2008).

O conceito de eugenia, segundo Melo (2008), é polissêmico, de modo que varia ao longo dos tempos, de acordo com os arquétipos de "bom nascimento" estabelecidos por cada sociedade.

A eugenia, assim, seria a utilização da genética para o fim de melhoramento de futuras gerações, podendo-se evitar ou limitar predisposições a doenças ou mesmo selecionar os indivíduos conforme algumas características almejadas.

Ademais, as práticas eugênicas podem ser notadas desde sempre, estando marcadas na história da humanidade as tentativas de controle de transmissão dos traços hereditários, conforme Melo (2008).

Em relação ao eugenismo, Junges (1999) relata que a busca pelo ser humano perfeito é um propósito. Ressalta que essa ideologia tem suas raízes no século XVIII, sendo a expressão da fé secular no progresso contínuo e na possibilidade de criação do ser humano tido como "perfeito". Quem, todavia, não se encaixa nesse estereótipo de perfeição, não teria lugar. Veja-se que a experiência nazista em relação à pretensão de busca pela raça pura desapareceu, mas existe certa tendência por essa busca de perfeição, de maneira mais sofisticada, ou seja, a ideologia da superioridade do homem e da procura pelo ser humano primoroso permanece.

Ainda neste norte, expõe Junges (1999), que as novas biotecnologias reforçam ainda mais a ideia do ser humano perfeito, porque se pautam em dados genéticos e, hodiernamente, o eugenismo pode se fundamentar em pressupostos científicos. Assim, anomalias biológicas e psíquicas podem, e devem ser detectadas com antecedência, e, por conseguinte, eliminadas. Em consequência disso, pretende-se gerar sempre e cada vez mais o ser humano exato, eliminando as características que não se enquadrem em tal definição, por meio dos novos métodos de procriação assistida, testes pré-natais e até mesmo intervenções cirúrgicas sobre os próprios fetos.

Conforme o autor, no mais, os conceitos de ser humano incapaz, imperfeito ou incompleto vão introduzindo-se de maneira paulatina na medicina e nas práticas de saúde no que se relaciona à matéria pré-natal. Desse modo, de maneira diversa da medicina curativa, 
que busca sanar ou aliviar a disfunção biológica de alguém, a medicina preditiva visa detectar os defeitos biológicos, para, então, corrigi-los ou, caso isso não seja possível, não deixar nascer quem é portador de imperfeição. Veja-se que, sob este aspecto, as biotecnologias conferem novas dimensões à definição de homem perfeito.

Enumera Junges (1999), ainda, que a despeito dos inúmeros benefícios, a medicina preditiva poderá trazer inúmeros desvirtuamentos. A primeira questão levantada é o reducionismo genético que ressalta apenas o fator gene, desconsiderando o fator meio ambiente. Para ele, é perigoso reduzir a doença apenas ao determinismo genético, de modo que a genética pode levantar falsas esperanças e fazer juras desmesuradas, não cumpridas após, devido à desconsideração de outros fatores importantes.

Entra em pauta, assim, as questões relacionadas à escolha, por parte dos ascendentes, de características desejadas em seus descendentes, tanto físicas quanto intelectuais, bem como a opção por determinado sexo, dentre outras questões extremamente delicadas.

Quanto a esta questão, Junges (1999) relaciona que elementos de cunho sociocultural podem entrar em cena, como a preferência por um filho de determinado sexo, sendo forçoso crer que, neste sentido, a ciência genética poderia fornecer instrumentos para a discriminação de gênero. Também, poderia culminar, até mesmo em certo tipo de discriminação racial, fundada em questões de saúde, quando testes genéticos demonstram que uma ou outra etnia poderia ter mais propensão ao desenvolvimento de algumas doenças ou anomalias.

Nesta mesma senda, Melo (2008) reitera que a aplicação de técnicas preconizada pelo eugenismo enquanto doutrina sociopolítica pode conduzir, ao longo dos tempos, a tratamentos desiguais. É necessária, assim, a intervenção do legislador, para regular o uso das práticas eugênicas. O Direito, assim, sempre teve relações próximas com o eugenismo, tendo a lei assumido com frequência a função de imposição de medidas impeditivas da violação do princípio da igualdade, no que se relaciona à constituição biológica da pessoa.

Essa é justamente a preocupação de Jürgen Habermas, ou seja, até que ponto a genética pode ser benéfica, e qual é o limiar para que venha a se tornar uma facilitadora de questões negativas, até mesmo em relação ao futuro indivíduo, que foi manipulado geneticamente, para consigo mesmo, no que tange à sua autodeterminação, autocompreensão, e visão como participante do todo social, e visualização como par dos demais indivíduos.

Neste mesmo viés, relaciona Goodfield (1994), que a vida não pode ser manipulada de forma leviana, merecendo respeito e cuidado, e a preocupação com o indivíduo é recorrente, ao se perceber o entusiasmo com que os cientistas se utilizam das novas 
tecnologias biomédicas. O temor relaciona-se ao fato de, eventualmente, não se estar perdendo o respeito de uns pelos outros, e por aquilo que significa pertencer ao gênero humano.

Assim, forçoso é lembrar que a eugenia pode ser dividida em positiva e negativa, conforme as características de cada procedimento. É, aliás, o que se passa a analisar neste momento.

\subsection{Eugenia Positiva e Eugenia Negativa}

Analisado o conceito de eugenia, faz-se necessário relacionar a existência da denominada eugenia positiva, e da denominada eugenia negativa.

Segundo Oliveira e Hammerschmidt (2008), a eugenia positiva seria aquela relacionada à seleção de características fisiológicas desejadas. De seu turno, a eugenia negativa se relaciona à questão da utilização de métodos anticonceptivos, do aborto eugênico, ou até mesmo da morte do recém-nascido, com vistas à eliminação do descendente não desejado, portador de malformações.

Do mesmo modo, reitera Silva (2002), que a denominada eugenia positiva consiste no favorecimento à transmissão de caracteres genéticos tidos como desejáveis, mediante recursos como seleção de gametas e terapia gênica alternativa. Já a eugenia negativa seria aquela relacionada a se evitar a transmissão de caracteres genéticos ponderados como indesejáveis.

Reitera Silva (2002), ainda, que a eugenia positiva parece não lembrar da heterogeneidade da composição genética da espécie humana. Já a eugenia negativa, embasada na crença da eliminação de genes defeituosos a longo prazo, da mesma forma parece esquecer que estes mesmos genes são muito difundidos na espécie humana, não sujeitando seu controle a meras ações pontuais, além do que, as mutações genéticas possuem a tendência de ocorrer naturalmente, mesmo que se faça a utilização de referidas práticas.

Aliás, conforme Habermas (2010), há a necessidade de que se faça a distinção entre as designadas eugenia positiva e eugenia negativa. Segundo o autor, esta parece ser justificada enquanto aquela, ao menos inicialmente, semelha ser considerada injustificada. Ainda, o limite entre ambas não parece ser exatamente claro e estanque, e, assim sendo, há a existência de um paradoxo que necessita ser enfrentado, pois justamente nas dimensões onde os limites não são exatamente definidos há a necessidade de imposição de fronteiras precisas. 
A partir do conceito de eugenia, e visando à compreensão Habermasiana acerca do assunto, torna-se imprescindível fazer uma análise do que externou o autor na obra objeto do estudo como um todo, para após perquirir qual o seu posicionamento nas questões concernentes às dimensões ético-jurídicas da denominada e afamada eugenia liberal.

\section{O ENTENDIMENTO HABERMASIANO GLOBAL EXTERNADO NA OBRA "O FUTURO DA NATUREZA HUMANA"}

De primeiro plano, para a explicitação do motivo pelo qual se preocupa com o tema, e na busca de uma justificação da intervenção da filosofia no assunto, Habermas (2010) expõe, ainda no prefácio da obra "O Futuro da Natureza Humana", que parte da distinção entre a teoria kantiana e a ética do ser em si mesmo, exposta por Kierkegaard - Soren Aabye Kierkegaard, filósofo dinamarquês anti-hegeliano que se preocupou especialmente com a ética e com a religião, possuindo uma obra, de certa forma, autobiográfica, uma vez que sua obra e sua vida são dimensões praticamente inseparáveis, conforme Sampaio (2010).

Ainda, defende Habermas (2010) a ideia de que o pensamento pós-metafísico precisa impor-se uma moderação, ao tratar da tomada de posições definitivas no que toca à vida boa ou não fracassada.

Daí, Habermas (2010) levanta a questão referente à discussão desencadeada pela técnica genética, se pode a filosofia se permitir a mesma moderação também em questões concernentes à ética da espécie - lembra a conferência apresentada que se baseou no texto "Moderação justificada".

Segundo ele, o texto da obra em comento se imiscui nesta discussão, onde ele próprio adota a perspectiva de um futuro próximo, onde um dia se lançará um olhar retrospectivo às práticas hoje objetadas, considerando-as como precursoras de uma eugenia liberal, regulada pela oferta e pela procura.

O perigo que circunda diz respeito à possibilidade de "criação de humanos". A despeito disso, os objetivos terapêuticos nos quais da mesma forma todas as intervenções de técnica genética deveriam se pautar, impõem escassos limites a possíveis interferências.

Neste norte, na perspectiva da filosofia enquanto forma de refletir sobre o assunto, relata Habermas (2010) que, ainda nos dias atuais a filosofia prática não renuncia de forma 
total a reflexões normativas, mas na sua totalidade, ela se limita a questões sobre a justiça. Ainda, se esforça de maneira especial para esclarecer o ponto de vista moral que se adota para julgar normas e ações sempre que se trata de estabelecer o que é de igual interesse de cada um e igualmente bom para todos.

Coloca que, parece a teoria moral e a ética se deixarem guiar por perguntas concernentes a "o que eu devo fazer" e "o que devemos fazer".

Porém, as teorias de hoje acerca da justiça e da moral trilham caminhos próprios, diferentes daquele da ética, tomada esta no sentido clássico de uma doutrina de vida correta.

Nas questões de maior relevância, relata Habermas (2010), assim, que a filosofia se desloca para um plano superior, analisando somente as propriedades formais dos processos de autocompreensão, sem, contudo, adotar ela mesma uma posição a respeito dos conteúdos.

Não obstante, conforme Feldhaus (2005), embora a filosofia não tenha a função de estudar o que constitui a vida correta às sociedades pluralistas contemporâneas, no que toca aos indivíduos e aos grupos de indivíduos, a biotecnologia abre espaço para uma discussão acerca do conceito de vida boa, no sentido de saber-se qual é a identidade que a humanidade como um todo deseja, ou não, assumir.

Deste modo, Habermas se imiscui na relevante contenda acerca da eugenia, buscando argumentos do ponto de vista filosófico para levantar questionamentos e tentar esclarecê-los, a despeito de o tema ser substancialmente controverso e poder gerar ambiguidades.

Acerca da discussão que propõe na obra, Habermas (2010) relaciona com frequência o Diagnóstico Genético de Pré-implantação, ou DGPI - sigla que menciona constantemente para substituir a expressão completa -, e explica que tal procedimento torna possível submeter o embrião, que se encontra em um estágio de oito células, a um exame genético de precaução. De maneira inicial, esse processo é posto à disposição daqueles pais que buscam evitar o risco de transmissão de doenças hereditárias, de modo que caso confirmado que existe alguma doença, o embrião analisado na proveta não é reimplantado na mãe, sendo esta poupada de uma futura interrupção da gestação, que seria efetuada após o diagnóstico pré-natal.

A partir daí seguem-se questionamentos filosóficos acerca de até onde a ciência pode chegar, e acerca dos limites éticos à intervenção da genética.

Habermas (2010) mostra-se apreensivo, outrossim, pois com o Diagnóstico Genético de Pré-implantação, torna-se difícil respeitar a fronteira entre a seleção dos fatores hereditários que são indesejáveis, e a otimização dos fatores desejáveis, ou seja, o limite 
conceitual entre a possibilidade de que se previna o nascimento de um ser humano gravemente doente, e o aperfeiçoamento do patrimônio hereditário, que se trata de uma decisão eugênica, não encontra limites muito bem delineados, e essa falta de limites conceituais entre prevenção e eugenia passa a ser uma questão política.

Quando trata, em seu texto, de decisões eugênicas e da polêmica advinda de tais circunstâncias, Habermas menciona constantemente, e toma por base, a eugenia liberal, que, por conseguinte, parece complementar o conceito genérico eugenia.

Portanto, assiste a premente necessidade de vislumbrar-se do que se trata a afamada eugenia liberal, cerne da discussão esposada na obra Habermasiana "O Futuro da Natureza Humana".

\subsection{A Eugenia Liberal por Jürgen Habermas}

Quando se diferenciou a eugenia positiva da eugenia negativa, mencionou-se os limites nada definidos entre ambas, e, inclusive, explicitou-se que, é justamente onde estes limites são pouco precisos que se precisa impor barreiras maciças, encontrando-se aí, verdadeiro paradoxo. O paradoxo é confrontado pela intenção de se conter as intervenções genéticas que beiram o limite do aperfeiçoamento genético de características, segundo o entendimento exarado por Habermas (2010).

Daí, coloca o autor que, hodiernamente, este argumento tem servido de escopo para a defesa de uma eugenia liberal. Esta, como externado por ele, não respeita ou reconhece limites entre intervenções terapêuticas e de aperfeiçoamento, deixando às preferências individuais dos integrantes do mercado a escolha dos objetivos relativos a intervenções que alteram características.

Deste modo, a eugenia liberal, conforme o próprio nome sugere, não traça limites entre o que pode ser feito com o intento de prevenir futuras doenças ou malformações genéticas, e as intervenções de "aperfeiçoamento da espécie", com a escolha de características desejadas. Assim, os limites conceituais entre a questão da prevenção de que um ser humano com graves problemas de saúde venha a nascer, e o puro e simples aperfeiçoamento do patrimônio hereditário, não é verdadeiramente balizado.

Nesta, ainda, conforme se amealha do texto de Corrêa (2005), o desenho de seres humanos, na pretensão de longevidade, perfeição física, ou qualquer outra característica hipotética, passa a ser livremente conjecturado, de modo que o cenário futuro vislumbrado por 
tal prática é aquele no qual as capacidades físicas, a inteligência, a beleza, e a longevidade, poderiam ser manipulados pela terapia ou pela engenharia genética.

Feldhaus (2005), inclusive, relata que Habermas explicita a eugenia liberal como aquela que visa o aperfeiçoamento da raça humana seguindo o fluxo demandado pelo mercado e, da mesma maneira, estabelecido pelas preferências individuais.

Assim sendo, controvérsias surgem sobre até onde se pode chegar em nome da ciência, e, da mesma forma, acerca da possibilidade de, com base em uma possível eugenia liberal, estar-se contrariando interesses do indivíduo que sofreu a intervenção. É o que discute o estudo a partir de agora.

\section{EUGENIA LIBERAL: FERIMENTO À AUTOCOMPREENSÃO E CONSEQUENTE DIGNIDADE PESSOAL DO INDIVÍDUO MANIPULADO GENETICAMENTE?}

Existe o entendimento de que, ao se realizar a manipulação genética, e, especificamente, com a eugenia liberal, estar-se-ia ferindo a dignidade do ser em formação que, por óbvio, futuramente será adulto e consciente dos procedimentos aos quais foi submetido-, e a própria autonomia, eis que seu direito de autodeterminação e principalmente, autocompreensão, seriam deveras mitigados por uma decisão de terceiro, normalmente dos pais, antes mesmo de seu nascimento.

Assim, Habermas (2010) demonstra sua preocupação em relação ao denominado DGPI (Diagnóstico Genético de Pré-implantação), que, para além dos benefícios, pode, de certa forma, oferecer perigos. Neste norte, a apreensão por conta da autonomia é recorrente, eis que esta é pressuposto para a autocompreensão do ser humano, e para a sua futura participação na esfera pública.

Veja-se que, todos os indivíduos apresentam a necessidade de autocompreenderemse e de se sentirem incluídos no ambiente social do qual fazem parte, e, saber que alguém decidiu por si as características que estes mesmos indivíduos deveriam vir a ter, quando eles ainda eram um amontoado de células, pode gerar um conflito interno e o ferimento à sua autocompreensão, e sentimento de entes participantes do todo social.

Neste norte, acerca do assunto, enumera Habermas (2010) que, a manipulação de genes se relaciona à própria identidade da espécie, de modo que a autocompreensão do homem enquanto ser desta espécie faz parte, também, do contexto em que se inscrevem o direito e a 
moral. Relaciona, ainda, que interessa especificamente a ele a questão da distinção feita entre "o que cresceu naturalmente" e "o que foi fabricado", como questão que muda a autocompreensão ética da espécie e afeta a concepção que o indivíduo geneticamente programado tem de si mesmo, eis que o conhecimento de uma programação eugênica do próprio patrimônio hereditário limita a configuração autônoma da vida da pessoa e mina as relações entre os iguais.

Por falar em identidade, Habermas (2010) coloca que, quando se trata da identidade enquanto ser da espécie, diversas concepções concorrem entre si. As representações naturalistas do homem, verificadas na linguagem da física, da neurologia ou da biologia evolucionista, concorrem com as concepções clássicas do homem, exteriorizadas pela religião e pela metafísica. Ainda, embora estejam em um nível mais elevado de generalização, as reflexões no que toca à ética da espécie dividem tanto com as reflexões ético-existenciais do indivíduo quanto com as ético-políticas das nações a referência a um contexto de vida particular, apropriado pela interpretação. Do mesmo modo, neste caso, a investigação cognitiva para saber como os seres humanos devem se compreender enquanto exemplares da espécie humana, a partir do conhecimento de fatos antropológicos relevantes, se junta à reflexão que avalia como cada qual pretende se compreender.

É justamente aí que o embate concernente à intervenção genética em seres humanos passa a ser tão relevante em um ponto de vista filosófico. Habermas (2010) acrescenta que, hodiernamente, é ainda assustadora a perspectiva de que a autoinstrumentalização otimizante da espécie, que, por assim elencar, será desenvolvida para que sejam satisfeitas as preferências distintas dos "clientes no supermercado genético", - expressão utilizada por ele próprio-, modifique o status moral dos futuros seres humanos.

Inclusive, o autor pondera que, a aplicação da técnica de pré-implantação está atrelada à questão normativa referente a ser, ou não, compatível com a dignidade humana ser gerado diante de ressalvas, e apenas após um exame genético ser tido como digno de poder existir e se desenvolver, indagando-se sobre a possibilidade de disposição da vida humana para fins de seleção.

Note-se que a preocupação em relação à compreensão que o ser humano manipulado geneticamente terá de si mesmo quando souber ter sido produto da vontade deliberada de terceiros é recorrente no texto de Jürgen Habermas, e sua preocupação tem toda a razão de ser, uma vez que a autocompreensão deste indivíduo e, consequentemente, a sua dignidade pessoal, podem ter sido mitigadas, sendo ele usado para satisfação de vontades alheias. 
Oportunamente, esclarece o autor que, a eugenia liberal precisa indagar-se acerca do fato de se, em algumas circunstâncias, o fato de a pessoa perceber a ausência de diferenciação entre o que cresce naturalmente e o que é fabricado, ou entre o subjetivo e o objetivo, não poderia gerar consequências para sua conduta autônoma de vida e para sua autocompreensão moral. Deve-se, assim, anteriormente de proceder a uma avaliação normativa, adotar a perspectiva das pessoas envolvidas.

Neste norte, Habermas (2010) coloca que, quando o indivíduo em crescimento, manipulado de forma eugênica, descobre a si, e ao seu corpo como algo fabricado, a sua perspectiva entra em choque com a perspectiva dos "produtores", uma vez que, ao decidir sobre o programa genético, os pais ambicionaram o que mais tarde se reverterá em expectativas em relação ao filho, mas sem conceder a este a mínima possibilidade de haver uma reconsideração, eis que uma vez efetuado o procedimento, não há como voltar atrás. A experiência é unilateral, dos pais em relação ao filho e não deste em relação a si mesmo, os pais tomam a decisão tendo em mente as suas preferências, contudo, a intervenção pode ter consequências existenciais irreversíveis para o ser em crescimento.

O que Habermas (2010) frequentemente traz à baila é o fato de que, o ser sujeito à eugenia liberal poderá, no futuro, não se identificar com as características escolhidas para ele, ou seja, não quer dizer que o indivíduo queira ser um expert em matemática, somente pelo fato de que os pais assim o desejaram quando ele ainda era um amontoado de células - veja-se que a ciência parece caminhar para a possibilidade de tais escolhas em detrimento da pura e simples detecção de doenças na fase embrionária.

Coloca com preciosidade, que, sim, este mesmo indivíduo poderá optar por desenvolver outro talento, mas que restará o incessante questionamento sobre como seria se ele tivesse sido "naturalmente desenvolvido", ou seja, não ter sido geneticamente modificado, e, mais, restará o peso da decisão entre apostar no talento escolhido pelos pais, em detrimento das próprias vontades, ou deixá-lo de lado com a constante ideia do que poderia ter acontecido caso ele fosse fomentado.

Veja-se, pode ser que a vontade dos pais coincida com a vontade do filho no futuro, e pode ser até mesmo que esse filho aprove as decisões dos pais, mas isso não é algo certo, e necessita ser questionado do ponto de vista da moralidade, e também do ponto de vista jurídico-normativo.

Conforme Habermas (2010), essa relação interna da ética da proteção à vida com a forma pela qual as pessoas se compreendem enquanto seres autônomos e iguais, orientados 
por fundamentos morais, torna-se evidente diante do pano de fundo de uma possível eugenia liberal. As razões morais que podem ser levantadas em face de tal prática, da mesma forma, desabonam as técnicas que preparam o caminho para uma eugenia liberal. Na atualidade, deve haver o questionamento se, eventualmente, as futuras gerações vão se conformar com o fato de não se conceberem mais como autoras únicas de suas vidas e de não mais serem responsabilizadas como tal.

É neste momento que Habermas (2010) questiona que, será que as gerações futuras se contentarão com uma relação interpessoal, não mais adaptada às condições igualitárias da moral e do direito?

Ainda, Jürgen Habermas pondera que é inquietante a perspectiva de uma prática de intervenções da técnica genética que modifique características, superando esta técnica os limites da relação básica comunicativa entre médico e paciente, e entre pais e filhos, minando, consequentemente, as formas de vida normativamente estruturadas através da autotransformação eugênica.

Assim, Habermas (2010) traz como limitador da eugenia liberal o fato de que o procedimento é irreversível, eis que, uma vez manipulada e modificada a herança genética, não há o que voltar atrás. Coloca o autor, que a irreversibilidade das consequências de manipulações genéticas feitas sobre uma decisão unilateral significa, de fato, uma responsabilidade problemática para aquele que se considera capaz de tomar uma decisão tão invasiva.

Também, argui que as práticas da eugenia de aperfeiçoamento não devem ser tidas como normais, de modo legítimo, em uma sociedade pluralista e democrática, que confere a todo o cidadão direito igual a uma vida autônoma, pois a seleção das disposições desejadas a priori não pode e não deve ser separada do pré-julgamento de determinados projetos de vida.

Logo, Habermas anuncia que, a eugenia liberal como um processo de heterodeterminação poderá reverter em questões negativas, tanto em relação à possibilidade de não compreensão do indivíduo para consigo próprio e como ser pertencente à "espécie" humana, quanto em relação à questão de não se entender como autor único de sua própria vida, eis que mero produto da intervenção de terceiros, subjugado à vontade alheia. Em relação à humanidade em geral, parece ser polêmico o caso, da mesma forma, eis que a própria indisponibilidade da vida humana poderia ser colocada em cheque.

Vislumbra-se, assim, que o avanço cada vez mais acelerado da ciência e das técnicas que, em princípio foram desenvolvidas para buscar o bem estar da humanidade, podem, como 
um efeito bumerangue, voltar-se para a humanidade de maneira não tão boa assim, trazendo dúvidas sobre o real alcance da tecnologia sobre a vida humana, como no caso em pauta, em que a engenharia genética pode servir de base para a uma mudança brusca e invasiva na existência de um ser, antes mesmo de seu nascimento.

\section{CONCLUSÃO: CONSIDERAÇÕES FINAIS}

A discussão sobre a eugenia e uma possível “construção de seres humanos”, com estes mesmos seres humanos "brincando de Deus", remonta à antiguidade. Nos dias hodiernos, com o avanço da ciência cada vez mais acelerado, a controvérsia se torna ainda mais onipresente, pois, parece mais palpável que se possa, de fato, em um futuro próximo, interferir na vida de outrem, escolhendo características desejáveis, ainda na fase pré-pessoal.

Sob esse parâmetro, a procura pela "criação" do homem perfeito, com cada vez menos defeitos, tanto do ponto de vista da saúde quanto do ponto de vista estético e mesmo intelectual, merece atenção.

Assim, a tecnologia que foi desenvolvida a priori para trazer benefícios à humanidade, trouxe consigo problemas a serem pensados, pela possível falta de limites em sua utilização.

No presente estudo, então, buscou-se fazer a análise do pensamento de Jürgen Habermas sobre o assunto, externado na obra "O Futuro da Natureza Humana", procurandose analisar se, com o denominado Diagnóstico Genético de Pré-implantação, e a possibilidade de uma futura eugenia liberal, as prerrogativas da pessoa submetida a tais procedimentos poderiam ser feridas.

O que se amealhou é que, se a humanidade está a caminho de uma eugenia liberal, questões éticas, morais e jurídicas surgem, até porque, a interferência nas escolhas futuras do indivíduo traz uma série de consequências não tão boas assim para quem foi "objeto" de uma modificação genética.

Como o próprio título indica, Habermas se preocupa com o futuro da humanidade no sentido de que, como poderão se comportar os sujeitos que futuramente possam se descobrir produtos da vontade deliberada dos próprios pais?

Não há que se questionar, não obstante, as contribuições que a engenharia genética trouxe, e ainda trará, no que concerne a uma possível prevenção de doenças, com base em 
diagnósticos realizados no embrião. Ocorre que, a dúvida cerca a questão de, até onde estão traçados os limites entre as intervenções terapêuticas e as intervenções de aperfeiçoamento da espécie, visando o ser humano perfeito?

Deveras, as ponderações Habermasianas são profundamente relevantes, pois, a autocompreensão do ser humano enquanto pertencente à espécie e enquanto participante igual do universo social, depende de uma série de fatores e, com certeza, enxergar-se como um ser produzido conforme os desejos alheios pode afetar essa compreensão.

Repare-se que a autocompreensão, reiteradamente utilizada na obra Habermasiana, refere-se à própria construção da identidade de cada indivíduo, um processo que por si só já é impregnado de percalços e que, sem dúvidas, no caso da intervenção genética, poderá restar deveras prejudicado.

Hoje, os talentos e as características psicológicas e físicas ainda são tidos como produto do acaso. Não que a carga genética não interfira, mas, veja-se, ninguém manipulou, a natureza simplesmente agiu para que cada ser humano seja como é. Assim, cada qual pode desenvolver um talento ou aptidão, ou autocompreender-se no meio, como igual a todos os demais, não nas características, mas na forma com que elas foram determinadas.

Em um futuro próximo, essa mesma visão de si próprio, pelo entendimento que Habermas expõe na obra, pode ser distorcida, e a vida pode vir a ser acompanhada de dúvidas e inseguranças originadas pela própria forma com que a pessoa foi gerada, no sentido de não saber, a pessoa, de fato quem é, ou quem seria se fosse "fruto do acaso".

Ferido, então, o direito de autocompreensão do sujeito, por consequência, a sua dignidade pessoal seria, de fato, ferida, pois a maneira como a pessoa se percebe enquanto ser humano, faz parte da sua dignidade, e da sua percepção enquanto indivíduo possuidor desta mesma dignidade, de modo que a engenharia genética, com a manipulação e consequente possível eugenia liberal, a despeito de poder trazer contribuições, poderá gerar uma lesão a direitos do indivíduo.

Assim, de fato, perceber-se digno é algo que passa pela construção da identidade pessoal de cada sujeito, ou seja, o modo como o indivíduo se enxerga, analisando-se do interior para o exterior, é condição primária para que a sua dignidade pessoal seja preservada, na medida em que sua autocompreensão é parâmetro para essa mesma dignidade.

Por fim, o que se enfrentou com o estudo em pauta foi uma questão hipotética, na visão de um renomado filósofo, que buscou considerar o que poderá vir a ocorrer em um presente vindouro. Porém, este presente vindouro parece estar cada vez mais próximo, 
restando premente o dia em que, de fato, a filosofia, e o próprio direito, terão de enfrentar tal problema, cotidianamente.

\section{REFERÊNCIAS}

CORRÊA, Marilena. O Admirável Projeto Genoma Humano. In: Débora Diniz (Org.). Admirável Nova Genética: Bioética e Sociedade. Brasília: UnB, 2005. p. 45-71.

FELDHAUS, Charles. O Futuro da Natureza Humana de Jürgen Habermas: Um comentário. Revista Internacional de Filosofia da Moral, Florianópolis, v. 4, n. 3, p. 309-319, 2005. Disponível em: https://periodicos.ufsc.br/index.php/ethic/article/view/20241/18613. Acesso em: 16 jul. 2015.

GOODFIELD. Brincando de Deus: a engenharia genética e a manipulação da vida. Tradução Regina Regis Junqueira. Belo Horizonte: Itatiaia, 1994. 208 p. Tradução de: Playing God: genetic engineering and the manipulation of life.

HABERMAS, Jürgen. O Futuro da Natureza Humana: A caminho de uma eugenia liberal? Tradução Karina Jannini. 2. ed. São Paulo: Marins Fontes, 2010. 159 p. Tradução de: Die Zukunft Der Menschlichen Natur: Auf Dem Weg Zu Einer Liberalen Eugenik?

JUNGES, José Roque. Bioética perspectivas e desafios. São Leopoldo: Unisinos, 1999. 322 p.

MELO, Helena Pereira de. Manual de Biodireito. Coimbra: Almedina, 2008. 299 p.

OLIVEIRA, José Sebastião de; HAMMERSCHMIDT, Denise. Genoma Humano: Eugenia e Discriminação Genética. Revista Jurídica Cesumar, Maringá, v.8, n. 1, p. 179-191, 2008.

Disponível em:

<http://periodicos.unicesumar.edu.br/index.php/revjuridica/article/view/728/564>. Acesso em: 16 jul. 2015.

SAMPAIO, Laura Cristina Ferreira. A existência ética e religiosa em Kierkegaard: continuidade ou ruptura? 2010. $180 \mathrm{f}$. Tese (Doutorado em Filosofia) - Universidade Federal de São Carlos, São Carlos, 2010. Disponível em:

<http://www.dfmc.ufscar.br/uploads/publications/4f04957cdcc7d.pdf >. Acesso em: 22 jul. 2015.

SILVA, Reinaldo Pereira e. Introdução ao Biodireito: Investigações político-jurídicas sobre o estatuto da concepção humana. São Paulo: LTr, 2002. 391 p. 